Tropical Journal of Pharmaceutical Research May 2021; 20 (5): 1003-1007

ISSN: $1596-5996$ (print); 1596-9827 (electronic)

(C) Pharmacotherapy Group, Faculty of Pharmacy, University of Benin, Benin City, 300001 Nigeria.

Available online at http://www.tjpr.org

Original Research Article

http://dx.doi.org/10.4314/tjpr.v20i5.17

\title{
Vasodilating effect of Hypericum revolutum (Vahl) (Clusiaceae) methanol extract in rats
}

\author{
Noha Z Timraz', Hany M El-Bassossy2, Sabrin RM Ibrahim ${ }^{3,4}$, Ali M El- \\ Halawany ${ }^{5}$, Ibrahim A Shehata ${ }^{5}$, Omar S Aljohani ${ }^{1}$, Hossam M Abdallah ${ }^{1,5 *}$ \\ ${ }^{1}$ Department of Natural Products and Alternative Medicine, Faculty of Pharmacy, King Abdulaziz University, Jeddah 21589, \\ Saudi Arabia, ${ }^{2}$ Department of Pharmacology, Faculty of Pharmacy, Zagazig University, Zagazig 44519, ${ }^{3}$ Batterjee Medical \\ College, PO Box 6231, North Obhur, Prince Abdullah Al-Faisal Street, 21442 Jeddah, Saudi Arabia, ${ }^{4}$ Department of \\ Pharmacognosy, Faculty of Pharmacy, Assiut University, Assiut 71526, ${ }^{5}$ Department of Pharmacognosy, Faculty of Pharmacy, \\ Cairo University, Cairo 11562, Egypt
}

*For correspondence: Email: hmafifi@kau.edu.sa; Tel: +966-544733110

Sent for review: 15 December 2020

Revised accepted: 22 April 2021

\begin{abstract}
Purpose: To investigate the vasodilating effect of Hypericum revolutum Vahl (Clusiaceae) in rats. Methods: $H$. revolutum aerial parts were extracted with methanol. The total methanol extract was fractionated with chloroform to yield fraction I. The remaining aqueous solution was chromatographed on Diaion HP-20 using water, $50 \%$ methanol, and methanol to yield three fractions (II- IV). Total methanol extract and fractions I-IV were applied to phenylephrine-pre-contracted $(10 \mu \mathrm{M})$ rat aortic rings at doses of 1,3 , and $10 \mu \mathrm{g} / \mathrm{mL}$. Subsequent decreases in aortic tension were recorded by an isometric force transducer to evaluate the vasodilation. Column chromatography was utilized to separate the active components of the bioactive fraction.

Results: Remarkable decreases in aortic tension $(p<0.05)$ revealed that fraction I (3 and $10 \mu \mathrm{g} / \mathrm{mL}$ ) produced a vasodilating effect, whereas fractions III and IV did not possess any substantial effect. Vasodilation induced by fraction I was endothelial-dependent because it was significantly $(p<0.05)$ blocked by endothelial denudation. Phytochemical inspection of fraction I led to the isolation of $\beta$ sitosterol (1), 1,7-dihydroxyxanthone (euxanthone) (2), and 2,3,4-tirmethoxy xanthone (3).

Conclusion: Fraction I of the $H$. revolutum extract was responsible for its vasodilating effect. This fraction may be used as a possible anti-hypertensive preparation after in vivo testing and successful clinical trials.
\end{abstract}

Keywords: Vasodilation, Hypericum revolutum, Clusiaceae, Nitric oxide

This is an Open Access article that uses a fund-ing model which does not charge readers or their institutions for access and distributed under the terms of the Creative Commons Attribution License (http://creativecommons.org/licenses/by/4.0) and the Budapest Open Access Initiative (http://www.budapestopenaccessinitiative.org/read), which permit unrestricted use, distribution, and reproduction in any medium, provided the original work is properly credited.

Tropical Journal of Pharmaceutical Research is indexed by Science Citation Index (SciSearch), Scopus, International Pharmaceutical Abstract, Chemical Abstracts, Embase, Index Copernicus, EBSCO, African Index Medicus, JournalSeek, Journal Citation Reports/Science Edition, Directory of Open Access Journals (DOAJ), African Journal Online, Bioline International, Open-J-Gate and Pharmacy Abstracts

\section{INTRODUCTION}

Medicinal plants use represents the basis of global healthcare. Medicinal plants are advantageous for treating various diseases. Most developing countries, particularly in Asia and
Africa, have reported a considerable increase in the use of such medications. Previous studies have shown that $>75 \%$ of the global population relies on herbal medicine [1]. The Saudi flora consists of approximately 2,250 plants that are equally disseminated all over the country [2]. A 
substantial number of these plants have been used by the locals for the management of hypertension [3]. Hypertension is a major worldwide problem that is frequently accompanied with metabolic syndrome, obesity, and diabetes. In fact, many people are at risk of cardiovascular diseases when they are affected by metabolic syndrome [4]. This is based on the fact that vascular destruction occurs as a result of oxidative stress and hyperglycaemia $[5,6]$. Vasodilators are an important class of antihypertensives to treat coronary artery disease and vascular insufficiency [7].

The Hypericum genus belongs to the Clusiaceae family, which was formerly known as Guttiferae [8]. Diversified Hypericum species possess antiviral, anti-inflammatory antioxidant, and antibacterial properties [9]. Naphthodianthrones, chlorogenic acid, phloroglucinols, flavonoids, xanthones, proanthocyanidins, phenylpropanes, benzofuran, and benzopyrans are widely reported from this genus [10-13].

General screening of the methanol extracts from some of the Saudi plants has revealed a promising vasodilating effect of $H$. revolutum. Therefore, this study targeted to determine the possible vasodilating potential of $H$. revolutum through a bio-guided approach using the isolated artery technique [14]. The methanol extract was fractionated to determine the bioactive fraction, which was then further fractionated to separate the bioactive compounds.

\section{EXPERIMENTAL}

\section{Extraction}

Plant material was collected from Al-Baha governorate (KSA), and was certified by $\mathrm{Dr}$ Emad Al- Sharif (taxonomist at Faculty of Science, Jeddah University). A specimen (\# HR0438) was preserved at the Department of Natural Products and Alternative Medicine's herbarium (KAU, Faculty of Pharmacy). Powdered $H$. revolutum aerial parts $(1 \mathrm{~kg})$ were extracted with cold methanol utilizing an Ultraturrex homogenizer. The pooled methanol extract was concentrated to yield a brown viscous extract. The total methanol extract was fractionated with chloroform to yield fraction I. The remaining aqueous solution was chromatographed in Diaion HP-20 using water, $50 \%$ methanol, and methanol to yield fractions (II-IV). Thin-layer chromatography revealed that fraction II was free from any phytochemical components. The chloroform fraction was subjected to $\mathrm{SiO}_{2} \mathrm{CC}$ (column chromatography) using an $n$-hexane:EtOAc gradient to yield compounds 1,2 , and 3 .

\section{Drugs and chemicals}

Acetyl choline (ACh), DMSO (dimethyl sulfoxide), and phenyl ephedrine (PE) were procured from Sigma-Aldrich (Dorset, UK).

\section{Animals}

Seven-week-old Wister male rats (200g) were supplied from the King Abdulaziz University`s animal facilities and were used in this study. The animal studies were legitimated by the Faculty of Pharmacy's Research Ethical Committee, King Abdulaziz University (approval no. 126-1439). The thoracic aortas were carefully excised after the rats were sacrificed by decapitation.

\section{Analysis of the direct vasodilating effect of the extract and its fractions}

Vasodilating effects of the total extract as well as its different fractions and pure isolates were assessed by the isolated artery technique, as formerly stated $[15,16]$. Briefly, the isolated aortic rings were suspended in a thermostatically controlled organ bath containing Krebs-Hens light buffer at $37{ }^{\circ} \mathrm{C}$. The aortic rings were subjected to $150 \mathrm{mg}$ of isometric tension, similar to physiological conditions in living animals, for 1 $\mathrm{h}$ before testing the vasodilating activities. Then, the aortic rings were pre-contracted with $10 \mu \mathrm{M}$ phenylephrine, followed by the cumulative addition of the total extract and fractions I, III, and IV. Only the vehicle was added in the time control group. The decreases in tension following each addition were noted by a sensitive isometric force transducer linked to a computer running Labchart v.8 software (ADInstruments, Australia). Endothelial tissues were mechanically denuded for additional analyses to examine the effect on vasodilation.

\section{Statistical analysis}

The obtained data were recorded as the mean \pm standard error of the mean (SEM) by two-way ANOVA (analysis of variance) followed by Dunnett's post hoc test. The analysis was carried out using GraphPad Prism software with a defined $\alpha$ of 0.05 .

\section{RESULTS}

Chemical examination of the $H$. revolutum chloroform fraction resulted the separation of three known compounds (1-3) (Figure 1). Their structures were confirmed by spectroscopic data 
$\left({ }^{13} \mathrm{C}\right.$ and ${ }^{1} \mathrm{H}$ NMR) and comparison with the available literature. The compounds were determined to be $\beta$-sitosterol (1) [17], 1,7dihydroxyxanthone (euxanthone) (2) [18], and 2,3,4-tirmethoxy xanthone (3) [19].

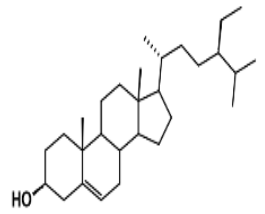

1

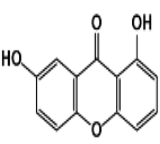

2

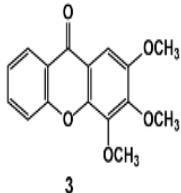

Figure 1: Isolated compounds (1-3) from $H$. revolutum

The vasodilating effect of methanol extract and fractions were examined using the isolated artery technique, as previously described $[15,16]$. Mechanical denudation of endothelial tissues was used for further investigation of the role of the endothelium in the observed vasodilating effect. Total methanol extract ( 3 and $10 \mu \mathrm{g} / \mathrm{mL}$ ) caused a significant decrease in tension $(p<0.05)$ and the subsequent vasodilation of phenylephrine (PE, $\left.10^{-6.5} \mathrm{M}\right)$ pre-contracted aorta in a dose-reliant manner (Figure 2).

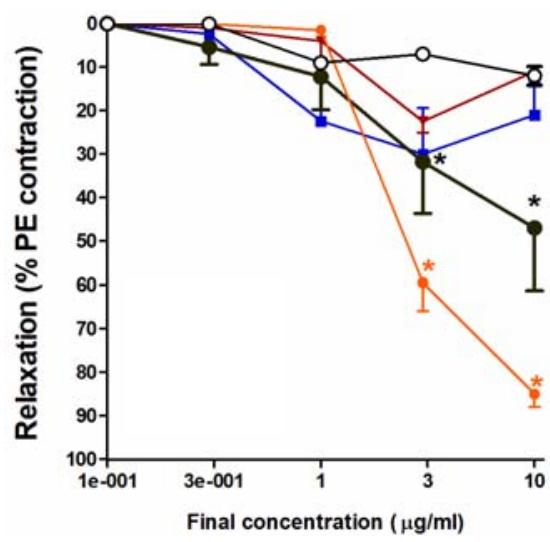

Figure 2: Effects of the total extract $\bullet$ and fractions I $\rightarrow$, III $\rightarrow$ and $\mathrm{VI} \rightarrow$ of $H$. revolutum on isolated aorta pre-contracted with phenylephrine (PE) compared with the time control -0 . Results are expressed as the mean \pm standard error of the mean (SEM, $n=8$ ). "Significantly varies from the corresponding time control values $(p<0.05)$ by two-way repeated measures ANOVA and the Newmans-Keuls post-hoc test

Bio-guided fractionation signified that chloroform fraction (fraction I) caused the vasodilating effect of the total extract because fraction I addition ( 3 and $10 \mu \mathrm{g} / \mathrm{mL})$ led to significant $(p<0.05)$ vasodilation, similar to that of the total methanol extract. Neither fraction III nor VI produced a significant effect (Figure 2). Removal of the endothelial layer by aorta denudation remarkably decreased the vasodilating effect of $H$. revolutum total extract $(3$ and $10 \mu \mathrm{g} / \mathrm{mL})(p<0.05)$ (Figure $3 \mathrm{~A})$. Likewise, the vasodilating impact of fraction I (3 and $10 \mu \mathrm{g} / \mathrm{mL}$ ) was also blocked by endothelial denudation $(p<0.05$, Figure 3 B).
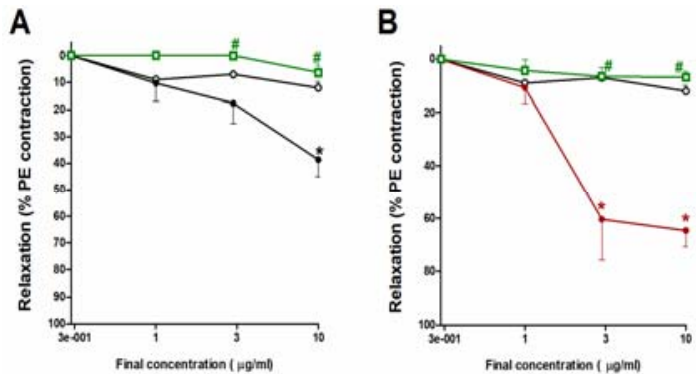

Figure 3: Effects of the total extract of $H$. revolutum (A) and fraction I $\rightarrow$ (B) on isolated endotheliumdenuded and normal aorta - compared with the time control -0 . Results were expressed as the mean \pm standard error of the mean (SEM) $(n=8)$. *Significantly varies from the corresponding time control values $(p<0.05)$. \#Significantly varies from the corresponding fraction I or total extract values $(p<0.05)$ by two-way ANOVA and the Newman-Keuls post-hoc test

\section{DISCUSSION}

Hypertension is a worldwide problem that is correlated with diabetes, obesity, and metabolic syndrome. Moreover, hypertension is the main cause of death due to the development of various cardiovascular diseases [4]. This is because vascular destruction occurs as a result of oxidative stress and hyperglycaemia [5,6]. In this regard, vasodilators are an important class of anti-hypertensives to treat coronary artery disease and vascular insufficiency [7]. Conventional vasodilators often show different side effects. Therefore, there is an urgent need for new bioactive anti-hypertensives with few or negligible side effects. Many medicinal plants have been examined for their vasodilating effects; however, only a few of them have shown pronounced activity [20].

The current study is the first to show that the $H$. revolutum total methanol extract induces a concentration-dependent vasodilation in phenylephrine pre-contracted isolated aortas. Bio-guided fractionation has demonstrated that the chloroform fraction is accountable for the vasodilation activity of the total extract. Similar vasodilation activity has been cited for other plant extracts, including the methanol extracts of Garcina mangostana and Mentha Iongifolia, which have been reported to produce direct vasorelaxation effects in response to phenylephrine-induced vasoconstriction and in 
an experimental model of angina, respectively $[21,22]$. The observed vasodilating effect of the plant extract may be due to its major bioactive components, and a review of the data has revealed that this effect may be attributed to the presence of xanthones and $\beta$-sitosterol.

Xanthones are reported to have potent antihypertensive activity through a calcium channel blocking mechanism [23]. It has been reported that 1,7-dihydroxyxanthone (euxanthone) (2) produces vasodilating effects through the repression of a calcium-sensitive mechanism accelerated by protein kinase $C$ [24]. Also, $\beta$ sitosterol (1) has been shown to ameliorate hypertension in rats through the restoration of basal liver and kidney functions [25]. Further studies are required to isolate other major compounds that may contribute to this vasodilating effect. In addition, a detailed mechanism of action for each of the isolated compounds will be considered for further publications.

\section{CONCLUSION}

The methanol extract from the aerial parts of $H$. revolutum exerts a significant vasodilating effect in a concentration dependent manner in rats. The vasodilating activity is endothelial-dependent and is attributed to the presence of xanthones and $\beta$ sitosterol, which have previously been investigated as vasorelaxants. These findings suggest that $H$. revolutum has potentials for treating hypertension; however, additional toxicological and clinical studies are warranted.

\section{DECLARATIONS}

\section{Acknowledgement}

This project was funded by King Abdulaziz City for Science and Technology, Kingdom of Saudi Arabia (no. P-S 1928-37).

\section{Conflict of interest}

No conflict of interest is associated with this work.

\section{Contribution of authors}

We declare that this work was done by all the author(s) named in this article and all liabilities pertaining to claims relating to the content of this article will be borne by the authors. The contribution of authors is given below for each role using their initials: conceptualization, Hossam M Abdallah and Ali M El-Halawany; methodology, Noha Z Timraz, and Hany M ElBassossy; validation, Noha Z Timraz, and Hany M El-Bassossy; formal analysis, Noha Z Timraz, and Sabrin RM Ibrahim; investigation, Noha Z Timraz, and Sabrin RM Ibrahim; resources, Hossam M Abdallah and Omar S Aljohani; data curation, Noha Z Timraz and Hossam M Abdallah; writing-original draft preparation, NT and $\mathrm{HB}$; writing-review and editing, Hossam M Abdallah, Ali M El-Halawany, Sabrin RM Ibrahim and Ibrahim A Shehata; visualization, Noha Z Timraz, and Hany M El-Bassossy; supervision, Hossam M Abdallah, Ali M El-Halawany and Ibrahim A Shehata; project administration, Hossam M Abdallah.

\section{Open Access}

This is an Open Access article that uses a funding model which does not charge readers or their institutions for access and distributed under the terms of the Creative Commons Attribution License (http://creativecommons.org/licenses/by/ 4.0) and the Budapest Open Access Initiative (http://www.budapestopenaccessinitiative.org/rea d), which permit unrestricted use, distribution, and reproduction in any medium, provided the original work is properly credited.

\section{REFERENCES}

1. Ekor M. The growing use of herbal medicines: issues relating to adverse reactions and challenges in monitoring safety. Front Pharmacol 2014; 4: 177.

2. Van Slageren M. Wildflowers of Saudi Arabia. Kew Bulletin. 2001; 56(4): 1021.

3. Neamsuvan O, Komonhiran P, Boonming K. Medicinal plants used for hypertension treatment by folk healers in Songkhla province, Thailand Journal of Ethnopharmacol. 2018; 214: 58-70. doi:10.1016/j.jep.2017.11.032

4. Galassi A, Reynolds K, He J. Metabolic syndrome and risk of cardiovascular disease: a meta-analysis. Am J Med 2006; 119(10): 812-819. doi:10.1016/j.amjmed.2006.02.031

5. Steinberg $H O$, Chaker $H$, Leaming $R$, Johnson $A$, Brechtel G, Baron AD. Obesity/insulin resistance is associated with endothelial dysfunction. Implications for the syndrome of insulin resistance. J Clin Invet 1996; 97(11): 2601-2610. doi:10.1172/jci118709

6. Tangvarasittichai S. Oxidative stress, insulin resistance, dyslipidemia and type 2 diabetes mellitus. World J. Diabetes 2015; 6(3): 456.

7. Fuchs C, Ertmer C, Rehberg S. Effects of vasodilators on haemodynamic coherence. Best Pract Res Clin Anaesthesiol 2016; 30(4): 479-489. doi:10.1016/j.bpa.2016.10.003

Trop J Pharm Res, May 2021; 20(5): 1006 
8. Xi-Wen L, Jie L, Robson NK, Stevens PF. Clusiaceae (guttiferae). Flora of China. 2007; 13: 1-47.

9. Décostered LA, Hostettmann $K$, Stoeckli-Evans $H$, Msonthi JD. New antifungal chromenyl ketones and their pentacyclic dimers from Hypericum revolutum Vahl. Helv Chim Acta 1987; 70(7): 1694-1702.

10. Wang D, Bai J, Sun F, Yang D. Chemical constituents and antidepressant activity of the new species Hypericum enshiense occurring in China. Phytomed 2010; 17(6): 410-413.

11. Patocka J. The chemistry, pharmacology, and toxicology of the biologically active constituents of the herb Hypericum perforatum L. J Appl Biomed 2003; 1(2): 6170.

12. Decosterd L, Stoeckli-Evans H, Msonthi J, Hostettmann K. A new antifungal chromene and a related dichromene from Hypericum revolutum. Planta Med 1986; 52(05): 429.

13. Shiu WKP, Gibbons S. Dibenzofuran and pyranone metabolites from Hypericum revolutum ssp. revolutum and Hypericum choisianum. Phytochemistry 2009; 70(3): 403-406.

14. Abdallah HM, Hassan NA, El-Halawany AM, Mohamed GA, Safo MK, El-Bassossy HM. Major flavonoids from Psiadia punctulata produce vasodilation via activation of endothelial dependent NO signaling. J Adv Res 2020; 24: 273-279. doi:10.1016/j.jare.2020.01.002

15. El-Bassossy HM, El-Fawal R, Fahmy A, Watson ML. Arginase inhibition alleviates hypertension in the metabolic syndrome. Br J Pharmcol 2013; 169(3): 693703

16. El-Bassossy HM, Elberry AA, Ghareib SA. Geraniol improves the impaired vascular reactivity in diabetes and metabolic syndrome through calcium channel blocking effect. J Diabetes Complications 2016; 30(6): 1008-1016.
17. Pierre LL, Moses MN. Isolation and characterisation of stigmasterol and $\beta$-sitosterol from Odontonema strictum (Acanthaceae). J Innov Pharm Biol Sci 2015; 2: 88-96.

18. Nagem TJ, Oliveira FFd. Xanthones and other constituents of Vismia parviflora. J Braz Chem Soc 1997; 8: 505-508.

19. Morel C, Séraphin D, Oger J-M, Litaudon M, Sévenet T, Richomme $P$, Bruneton J. New xanthones from Calophyllum caledonicum. J Nat Prod 2000; 63(11): 1471-1474.

20. Maione F, Cicala C, Musciacco G, De Feo V, Amat AG, lalenti A, Mascolo N. Phenols, alkaloids and terpenes from medicinal plants with antihypertensive and vasorelaxant activities. A review of natural products as leads to potential therapeutic agents. Nat Prod Commun 2013; 8(4): 1934578X1300800434.

21. Azhar AS, El-Bassossy HM, Abdallah HM. Mentha longifolia alleviates experimentally induced angina via decreasing cardiac load. J Food Biochem 2018: e12702.

22. Abdallah HM, El-Bassossy HM, Mohamed GA, EIHalawany AM, Alshali KZ, Banjar ZM. Phenolics from Garcinia mangostana alleviate exaggerated vasoconstriction in metabolic syndrome through direct vasodilatation and nitric oxide generation. BMC Complement Altern Med 2016; 16(1): 1-10.

23. Goshain O, Ahmed B. Antihypertensive activity, toxicity and molecular docking study of newly synthesized xanthon derivatives (xanthonoxypropanolamine). PLoS One. 2019; 14(8): e0220920.

24. Câmara DV, Lemos VS, Santos MHd, Nagem TJ, Côrtes SdF. Mechanism of the vasodilator effect of Euxanthone in rat small mesenteric arteries. Phytomedicine. 2010; 17(8-9): 690-692.

25. Olaiya C, Esan A, Alabi T. Ameliorative effects of $\beta$ sitosterol on some biochemical indices of hypertension in wistar albino rats. Afr J Med Med Sci 2014; 43(Suppl 1): 157. 